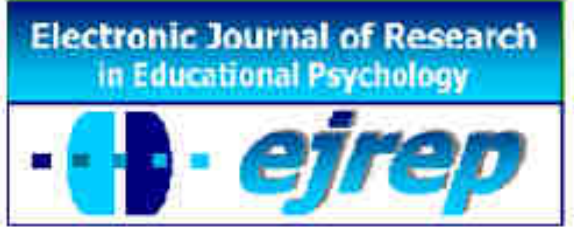

\title{
Stressful psychosocial work environment, poor sleep, and depressive symptoms among primary school teachers
}

\section{Kia Gluschkoff ${ }^{1}$, Marko Elovainio ${ }^{1,2}$, Liisa Keltikangas- Järvinen $^{1}$, Mirka Hintsanen ${ }^{3,1}$, Sari Mullola ${ }^{1}$ \& Taina Hintsa ${ }^{1}$}

\footnotetext{
${ }^{1}$ Institute of Behavioural Sciences, University of Helsinki, Helsinki

${ }^{2}$ National Institute for Health and Welfare, Helsinki

${ }^{3}$ Unit of Psychology, Faculty of Education, University of Oulu, Oulu
}

\section{Finland}

Correspondence: Kia Gluschkoff, Institute of Behavioural Sciences, P.O. Box 9, 00014 University of Helsinki, Finland. E-mail: kia.gluschkoff@helsinki.fi

(C) Education \& Psychology I+D+i and Ilustre Colegio Oficial de la Psicología de Andalucía Oriental (Spain) 


\begin{abstract}
Introduction. We examined the associations and proportionate contributions of three wellvalidated models of stressful psychosocial work environment (job strain, effort-reward imbalance, and organizational injustice) in explaining depressive symptoms among primary school teachers. In addition, we tested the mediating role of different types of sleep problems.
\end{abstract}

Method. The participants included 76 Finnish primary school teachers. The associations between the three work-related psychosocial factors, sleep problems, and depressive symptoms were examined using multiple linear regression analyses and bootstrap mediation analyses, adjusting for gender and age. Relative weight analyses were performed to examine the proportionate contributions of the work-related psychosocial factors on depressive symptoms.

Results. Both effort-reward imbalance and job strain showed positive associations with depressive symptoms, whereas the association between organizational injustice and depressive symptoms was not significant. When the proportionate contributions of job strain, effortreward imbalance, and organizational injustice on depressive symptoms were analysed simultaneously, effort-reward imbalance was found to be the most important predictor. According to bootstrap mediation analyses, sleep problems in terms of nonrestorative sleep explained $18 \%$ of the association between job strain and depressive symptoms and $11 \%$ of the association between effort-reward imbalance and depressive symptoms.

Conclusion. Our findings suggest that, for primary school teachers, particularly effort-reward imbalance but also job strain may be risk factors for depressive symptoms, and that this association might be partly explained by impaired sleep. Adjusting work demands and increasing the rewarding aspects of teachers' work may enhance sleep quality and reduce depressive symptoms in primary school teachers' occupation.

Keywords: work-related psychosocial factors, depressive symptoms, sleep problems, teachers. 


\section{Resumen}

Introducción. Examinamos las asociaciones y contribuciones proporcionales de los tres modelos validados de entorno psicosocial de trabajo estresante (tensión laboral, desequilibrio esfuerzo-recompensa, injusticia organizacional) con respecto a su potencial para explicar síntomas depresivos entre profesores de educación primaria. Adicionalmente, comprobamos el rol mediador de diferentes tipos de problemas de sueño.

Método. Los participantes fueron 76 profesores de primaria finlandeses. Las asociaciones entre los tres factores psicosociales relacionados con el trabajo, dificultades de sueño y síntomas depresivos fueron examinadas mediante análisis de regresión múltiple y análisis de mediación por bootstrap, ajustados por género y edad. Análisis de importancia relativa fueron llevados a cabo para examinar la contribución proporcional de los factores psicosociales relacionados con el trabajo sobre los síntomas depresivos.

Resultados. Ambos modelos de desequilibrio esfuerzo-recompensa y tensión laboral mostraron asociaciones positivas con síntomas depresivos, mientras que la asociación entre el modelo de injusticia organizacional y los síntomas depresivos no fue estadísticamente significativa. Cuando las contribuciones proporcionales de los tres modelos fueron analizadas simultáneamente, el de desequilibrio esfuerzo-recompensa se mostró como el predictor más importante. De acuerdo con los análisis de mediación por bootstrap, los problemas de sueño en términos de sueño no reparador explicaron el 18\% de la asociación entre la tensión laboral y los síntomas depresivos, y el $11 \%$ de la asociación entre el desequilibrio esfuerzo-recompensa y los síntomas depresivos.

Conlusión. Nuestros resultados sugieren que, entre los profesores de primaria, en particular el desequilibrio esfuerzo-recompensa pero también la tensión laboral podrían ser factores de riesgo para los síntomas depresivos, y que esta asociación quizá sea parcialmente explicada por dificultades en el sueño. El ajuste de las demandas laborales y una mejora de los aspectos gratificantes del trabajo de los profesores quizá contribuyan la calidad del sueño y reduzcan el riesgo de síntomas depresivos entre aquellos que ejercen como profesores de educación primaria.

Palabras Clave: factores psicosociales en el trabajo, síntomas depresivos, dificultades de sueño, profesores. 


\section{Introduction}

A stressful psychosocial work environment has been associated with an elevated risk of various mental health problems, including depression (Bonde, 2008; Nieuwenhuijsen, Bruinvels, \& Frings-Dresen, 2010). Working in one of the high stress professions (Johnson et al., 2005), teachers can be particularly at risk for depressive disorders. Depression has an adverse effect on the quality of life and it predicts various adverse health outcomes, such as type 2 diabetes (Mezuk, Eaton, Albrecht, \& Golden, 2008) and cardiovascular disease (Van der Kooy et al., 2007). Besides having negative implications on a personal level, teachers' depression can extend to affect the pupils by deteriorating the learning environment and the pupils' academic achievements (McLean \& Connor, 2015).

Prior research on the adverse effects of work-related psychosocial stress on mental health has focused on three theoretical models: the demand-control model (also known as job strain model), the model of effort-reward imbalance (ERI), and more recently, the model of organizational justice. In teaching, particularly perceptions of effort-reward imbalance have been linked to poor mental health (Loerbroks et al., 2014; Wang et al., 2014). However, it is currently not known what kind of explanatory power these three well-established models have on teacher mental health when they are compared simultaneously. We address this issue by examining the proportionate contributions of job strain, effort-reward imbalance, and organizational injustice in explaining depressive symptoms in teachers occupational setting.

According to the job strain model, the combination of high work demands (e.g., time pressure and workload) and low control (e.g., lack of authority to make decisions, no possibility to use creativity or skills at work) results in psychological strain (Karasek, 1979; Karasek \& Theorell, 1990). In the ERI model, work stress is caused by non-reciprocity between high efforts spent (e.g., working under time pressure and having many responsibilities) and low rewards received (in terms of money, esteem, career opportunities, and job security) (Siegrist, 1996; Siegrist et al., 2004). Although the job strain model and the ERI model share similar elements of work environment, their perspectives are somewhat different: the job strain model gives attention to the job content and power structure at work, whereas the ERI model considers also the social and economic aspects of work. The distinct contribution of these models in explaining poor mental health is reflected in their predictive power that varies between different occupations (Calnan, Wadsworth, May, Smith, \& Wainwright, 2004). 
The concept of organizational justice complements both the job strain and the ERI model by focusing on the fairness of managerial practices and decision-making processes at work. Justice at work comprises of distributional, procedural, and interpersonal elements: distributional justice refers to the perceived fairness of reward and resource allocation, procedural justice to the fairness of decision making processes, and interactional justice to the respectful interpersonal treatment and truthfulness of communication by management to employees (Colquitt, Conlon, Wesson, Porter, \& Ng, 2001; Greenberg, 1990). Along with the job strain and the ERI model, poor organizational justice has more recently been recognized as a significant work-related psychosocial health risk (Robbins, Ford, \& Tetrick, 2012).

In addition to examining the associations of job strain, effort-reward imbalance, and organizational injustice with depressive symptoms, we investigate the role of sleep problems as mediators in the associations. Previous research gives some indication of the significance of sleep as one of the mediating mechanisms through which stressful work characteristics affect mental health (Åkerstedt, 2006). Sleep is viewed as the most essential means of recovery, restoring alertness, memory capacity, and mood, but also regenerating central nervous system, metabolic system, endocrine system, and immune system (Åkerstedt, Nilsson, \& Kecklund, 2009). The role of work stress as an antecedent of sleep problems is well demonstrated (Van Laethem, Beckers, Kompier, Dijksterhuis, \& Geurts, 2013; Åkerstedt, Nordin, Alfredsson, Westerholm, \& Kecklund, 2012), as is the association between impaired sleep and poor mental health (Baglioni et al., 2011; Jansson-Fröjmark \& Lindblom, 2010). Although sleep can support recovery from stressful situations and thus prevent the development of chronic health problems, stress can also have an adverse effect on sleep (Geurts \& Sonnentag, 2006).

So far, the hypothesis on sleep as a mediator in the association between stressful psychosocial work environment and poor mental health has received support from two studies. First, lack of organizational justice was shown to predict minor psychiatric morbidity among Finnish hospital employees partly through sleep problems across a 2-year interval (Elovainio, Kivimäki, Vahtera, Keltikangas-Järvinen, \& Virtanen, 2003). More recently, sleep problems were found to mediate the relationship between job demands and prospective depressive symptoms in a longitudinal cohort study in Sweden (Magnusson Hanson, Chungkham, 
Åkerstedt, \& Westerlund, 2014). Whereas prior research has linked teachers' experiences of high job strain to poor sleep quality (Cropley, Dijk, \& Stanley, 2006), the mediating role of sleep in the association between work-related psychosocial stress and depressive symptoms remains to be investigated in teachers' occupation. Compared with other professions, teachers not only report more work-related stress and symptoms of poor mental health (Johnson et al., 2005) but have also higher levels of sleep deprivation (Amschler \& McKenzie, 2010). Enhancing the understanding of the role poor sleep plays in the development of depressive symptoms can contribute to the prevention of mental health problems among teachers.

\section{Aims and Hypotheses}

The first aim of this study was to examine the associations and proportionate contributions of three separate, well-validated models of stressful psychosocial work environment (job strain, effort-reward imbalance, and organizational injustice) to depressive symptoms in primary school teachers' occupation. Additionally, we examined the mediating role of sleep problems in the associations. Based on previous research we expect stressful work-related psychosocial factors to be positively associated with sleep problems (hypothesis 1) and depressive symptoms (hypothesis 2), sleep problems to be positively associated with depressive symptoms (hypothesis 3), and sleep problems to mediate the association between stressful work-related psychosocial factors and depressive symptoms (hypothesis 4).

\section{Method}

\section{Participants}

The sample comprised 76 primary school teachers instructing grades one through six (7-12 year old students). Of the teachers 66 were female and 10 were male, and their age ranged between 25 to 63 years $(M=43.95, S D=10.10)$. The age distribution $(33 \%<40$ years, 34\% 40-49 years, and 33\% $\geq 50$ years) and gender distribution (87\% female) were comparable to national age and gender distributions among teachers in Finland (Finnish National Board of Education, 2013). 


\section{Instruments}

Job strain. Job demands $(\alpha=.70)$ were measured with a 5-item scale (e.g., "Is your work emotionally demanding?") and job control $(\alpha=.62)$ with a 9-item scale (e.g., "I can make independent decisions at my work") from the Job Content Questionnaire (Karasek, 1985). The job demand items were rated on 5-point scale ranging from $1=$ never to $5=$ all the time and the job control items on a scale from $1=$ does not suit me at all to $5=$ suits me very well. The job strain indicator was formed by subtracting the mean job control score from the mean job demands score (Hintsanen et al., 2005).

Effort-reward imbalance. Effort-reward imbalance was measured with the original ERI measure (Siegrist, 1996), in which the effort scale $(\alpha=.64$ ) consisted 5 items (e.g., "I have constant time pressure due to a heavy work load") and the reward scale $(\alpha=.79)$ of 11 items (e.g., "Considering all my efforts and achievements, I receive the respect and prestige I deserve at work"). Responses were given on a 5-point scale ranging from $1=$ does not suit me at all to 5 = suits me very well. Effort-reward imbalance was calculated as a ratio between effort and reward (Siegrist et al., 2004).

Organizational justice. Organizational justice $(\alpha=.87)$ was assessed with a short 8item questionnaire (e.g., "The decision-making procedures have been applied consistently"). The items were rated on a 5-point scale ranging from $1=I$ totally disagree to $5=I$ totally agree. This short measure of justice has been shown to be associated with an increased risk of sleep problems and psychological distress among health care professionals (Elovainio et al., 2010). The justice score was reverse coded for the analyses.

Depressive symptoms. Depressive symptoms $(\alpha=.90)$ experienced during the past two weeks were self-rated with the Beck Depression Inventory II (BDI-II: Beck, Steer, \& Brown, 1996). The 21-item scale measures affective, cognitive, and somatic elements of depressive symptoms. Each item includes four response alternatives coded from 0 to 3 (e.g., from "I don't cry any more than usual" to "I used to be able to cry, but now I can't cry even though I want to"). Possible total scores range from 0 to 63 , the higher scores corresponding to higher levels of depressive symptoms. 
Sleep problems. Sleep problems were examined with the 4-item Jenkins sleep problems scale (Jenkins, Stanton, Niemcryk, \& Rose, 1988). The respondents were asked to rate along a 6 -point scale ranging from $0=$ not at all to $5=$ every night how often during the previous four weeks he/she experienced difficulty falling asleep, waking up several times per night, difficulty staying asleep (including waking far too early), and waking up feeling tired and worn out after the usual amount of sleep. The four items measure three components of sleep problems: the first item measures sleep onset problems, the second and third measure sleep maintenance problems, and the fourth measures nonrestorative sleep. The Jenkins sleep problems scale has been shown to offer good internal consistency and test-retest reliability (Jenkins et al., 1988).

Control variables. Participant gender and age were included as control variables. Both of them have been associated in previous studies with responsiveness to psychosocial stress (Kudielka, Buske-Kirschbaum, Hellhammer, \& Kirschbaum, 2004) and depressive symptoms (Bebbington et al., 2003).

\section{Procedure}

Questionnaire data were collected from a randomized selection of primary schools in the Helsinki metropolitan area of Finland during 2013-2014. The selection of primary schools $(N=48)$ represented around $25 \%$ of the total 189 primary schools in the area. At first, the school principal was contacted by telephone in order to acquire permission for the study. At this stage, nine of the 48 selected schools declined to participate in the study for various reasons (ongoing renovation at school, too busy to participate etc.). The permission to deliver the questionnaires was granted by the school principal to 39 schools, of which 34 schools actually participated in the study. The questionnaires were delivered in unnamed envelopes to the teachers' post boxes in the middle of the school term. The exact number of eligible teachers was not known due to limited information on the number of operating teachers per school and turnover in teacher personnel during the data collection period.

\section{Data analysis}

First, we examined Pearson correlations between the study variables. The associations between the work-related psychosocial factors, sleep problems, and depressive symptoms were then examined separately by a series of linear regression analyses, adjusting for gender and age. Next, a relative weight analysis was performed using a tool developed by LeBreton 
(Tonidandel \& LeBreton, 2011) in order to compare the proportionate contributions of job strain, effort-reward imbalance, and organizational injustice in explaining depressive symptoms. Relative importance refers to "the proportionate contribution each predictor makes to $R^{2}$, considering both its direct effect (i.e., its correlation with the criterion) and its effect when combined with the other variables in the regression equation" (Johnson \& Lebreton, 2004, p. 240). The method provides more precise information about the importance of multiple predictor variables than standardized beta weights when the predictors are correlated.

The mediating role of sleep onset problems, sleep maintenance problems, and nonrestorative sleep was examined separately by bootstrapping with a PROCESS macro for SPSS (Hayes, 2013). Bootstrapping is a preferred method for assessing indirect associations because it makes no assumptions about the shape of the distributions of the variables or the normality of the sampling distribution, and it is applicable even for smaller sample sizes (Preacher \& Hayes, 2008). Bootstrapped confidence intervals were used to determine the significance of the indirect effect through sleep problems in the association between workrelated psychosocial factors and depressive symptoms. All analyses were performed using SPSS Statistics 22.0.

\section{Results}

Table 1 presents the descriptive statistics and the correlations between the study variables. Several teachers $(56 \%)$ reported effort-reward imbalance (effort-reward ratio > 1) but comparatively smaller group ( $16 \%$ ) reported experiencing job strain (job strain indicator $>0$ ). The teachers reported moderate levels of perceived organizational justice $(M=3.42, S D=$ 0.82), which was comparable to previous findings among municipal employees (Perko \& Kinnunen, 2013). In terms of sleep problems experienced at least on two nights a week, 11\% of teachers reported having sleep onset problems, 9\% reported sleep maintenance problems, and $7 \%$ reported nonrestorative sleep. See Table 1. 


\section{Table 1}

Descriptive Statistics and Correlations Between the Study Variables

\begin{tabular}{|c|c|c|c|c|c|c|c|c|c|c|c|}
\hline Variable & $M$ & $S D$ & 1 & 2 & 3 & 4 & 5 & 6 & 7 & 8 & 9 \\
\hline 1. Gender ${ }^{\mathrm{a}}$ & 1.13 & 0.34 & - & & & & & & & & \\
\hline 2. Age & 43.95 & 10.10 & $.38^{* *}$ & - & & & & & & & \\
\hline 3. Job Strain & -0.86 & 0.88 & $-.28 *$ & -.17 & - & & & & & & \\
\hline 4. Effort-Reward Imbalance & 1.08 & 0.31 & -.08 & -.08 & $.56^{* *}$ & - & & & & & \\
\hline 5. Organizational Injustice & 2.57 & 0.82 & .07 & .04 & .18 & $.63^{*}$ & - & & & & \\
\hline 6. Sleep Onset Problems & 0.75 & 1.11 & -.09 & -.21 & .17 & .12 & .04 & - & & & \\
\hline 7. Sleep Maintenance Problems & 1.56 & 1.31 & -.11 & -.02 & .19 & .18 & .01 & $.51^{* *}$ & - & & \\
\hline 8. Nonrestorative Sleep & 1.68 & 1.25 & $-.28 *$ & $-.35^{*}$ & $.38^{* *}$ & $.28^{*}$ & .07 & $.59^{* *}$ & $.52^{* *}$ & - & \\
\hline 9. Depressive Symptoms & 5.42 & 5.90 & $-.25^{*}$ & -.19 & $.37 * *$ & $.41^{* *}$ & .07 & $.31^{* *}$ & .17 & $.38^{* *}$ & \\
\hline
\end{tabular}

Note. $N=73-76 . M=$ mean. $S D=$ standard deviation. ${ }^{a} 1=$ female, $2=$ male. $* p<.05 . * * p<.01$.

According to the results of regression analyses, higher job strain and higher effortreward imbalance were associated with experiences of nonrestorative sleep $(\beta=.34, p=.003$ and $\beta=.26, p=.016$, respectively) but not with sleep onset problems or sleep maintenance problems ( $\beta$ ranging from .10 to $.18, p$-values $>.05$ ) (hypothesis 1$)$. Furthermore, higher job strain and higher effort-reward imbalance were associated with higher depressive symptoms ( $\beta=.33, p=.006$ and $\beta=.40, p<.001$, respectively) (hypothesis 2 ). Organizational injustice was not associated with any of the sleep problems measured or with depressive symptoms ( $\beta$ ranging from .04 to $.12, p$-values $>.05$ ). Finally, sleep onset problems and nonrestorative sleep were associated with depressive symptoms $(\beta=.28, p=.019$ and $\beta=.29, p=.023$, respectively), while there was no significant association between sleep maintenance problems and depressive symptoms $(\beta=.13, p=.278)$ (hypothesis 3$)$.

Effort-reward imbalance was found to be the most important predictor of depressive symptoms, as it had the most explanatory power $(56.5 \%)$ in the relative weight analysis when examined simultaneously with job strain and organizational injustice. In addition, job strain had notable but non-significant contribution to the model (33.5\%), while the contribution of organizational injustice (10.0\%) was only marginal (Table 2). 
Table 2

Job Strain, Effort-Reward Imbalance, and Organizational Injustice

Predicting Depressive Symptoms in Relative Weight Analysis

\begin{tabular}{lll}
\hline Predictor & $\beta$ & $\begin{array}{c}\text { Relative } \\
\text { Weight }\end{array}$ \\
\hline Job Strain & .15 & $33.5 \%$ \\
Effort-Reward Imbalance & $.50^{* *}$ & $56.5 \%$ \\
Organizational Injustice & .28 & $10.0 \%$ \\
& & \\
$R^{2}$ & .24 & \\
$F$ & $6.97 * * *$ \\
\hline Note. $N=72$. Relative weights are presented as percentage of $R^{2}$. \\
$* * p<.01 . * * * p<.001$.
\end{tabular}

Table 3 presents the results of bootstrap mediation analyses. The bootstrap test of the indirect effect of job strain and effort-reward imbalance on depressive symptoms through nonrestorative sleep (adjusted for gender and age) showed a small but significant indirect effect $\left(\beta_{\text {indirect }}=.06, p<.05\right.$ and $\beta_{\text {indirect }}=.05, p<.05$, respectively) (hypothesis 4$)$. Nonrestorative sleep explained $18 \%$ of the association between job strain and depressive symptoms and $11 \%$ of the association between effort-reward imbalance and depressive symptoms. Sleep onset problems or sleep maintenance problems did not mediate the associations. Organizational injustice did not have an indirect effect on depressive symptoms through any of the sleep problems examined.

Table 3

Job Strain, Effort-Reward Imbalance, and Organizational Injustice Predicting Depressive Symptoms through Sleep Problems

\begin{tabular}{|c|c|c|c|c|c|c|}
\hline Predictor & Mediator & $\begin{array}{c}\text { Total Effect } \\
\text { on Depressive } \\
\text { Symptoms } \\
\end{array}$ & $\begin{array}{c}\text { Indirect Effect } \\
\text { on Depressive } \\
\text { Symptoms } \\
\end{array}$ & $\begin{array}{c}\text { BLCI } 95 \% \\
\text { for Indirect } \\
\text { Effect }\end{array}$ & $\begin{array}{c}\text { BUCI } 95 \% \\
\text { for Indirect } \\
\text { Effect }\end{array}$ & $\begin{array}{c}\text { Indirect / } \\
\text { Total Effect }\end{array}$ \\
\hline \multirow[t]{4}{*}{ Job Strain } & & $.33 * *$ & & & & \\
\hline & Sleep Onset Problems & & .04 & -.007 & .148 & $11 \%$ \\
\hline & Sleep Maintenance Problems & & .01 & -.019 & .102 & $4 \%$ \\
\hline & Nonrestorative Sleep & & .06 & .004 & .167 & $18 \%$ \\
\hline
\end{tabular}


Effort-Reward Imbalance

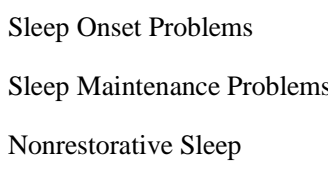

Organizational Injustice

Sleep Onset Problems

Sleep Maintenance Problems

Nonrestorative Sleep
$.40^{* * * *}$

$\begin{array}{rrrr}.01 & -.036 & .095 & 3 \% \\ .01 & -.016 & .084 & 3 \% \\ .05 & \mathbf{. 0 0 3} & \mathbf{. 1 3 3} & \mathbf{1 1 \%}\end{array}$

.12

$\begin{array}{rrrr}.01 & -.079 & .090 & 9 \% \\ .01 & -.039 & .070 & 6 \% \\ .02 & -.088 & .114 & 37 \%\end{array}$

Note. $N=69-73$. The effects are standardized betas, adjusted for gender and age. Significant results $(p<.05)$ are in bold characters. Direct effect of a predictor variable on depressive symptoms $=$ total effect - indirect effect. BLCI = bootstrap lower confidence interval. BUCI = bootstrap upper confidence interval.

$* * p<.01 . * * * p<.001$

\section{Discussion}

We examined the associations of three well-established models of stressful psychosocial work environmentand with depressive symptoms, and the mediating role of sleep problems among primary school teachers. The findings of our study suggest that, for primary school teachers, particularly effort-reward imbalance but also job strain may be risk factors for depressive symptoms, and that these associations could be partly explained by sleep problems in terms of nonrestorative sleep.

The observed associations of job strain and effort-reward imbalance with depressive symptoms support our hypothesis and are consistent with prior research linking stressful psychosocial work environment to mental health problems in teaching (Bauer et al., 2007; Hakanen, Bakker, \& Schaufeli, 2006; Steinhardt, Smith Jaggars, Faulk, \& Gloria, 2011). Our results on the relative strength of the ERI model in explaining depressive symptoms in teaching are in agreement with previous findings from a sample of Chinese teachers (Wang et al., 2014). The results may reflect the unique characteristics of the job strain and the ERI model: the job strain model measures work content related stress, while the ERI model takes into account also some of the social elements in the working environment, such as the respect and support the employee receives. Because teaching entails considerable amount of social interaction, the ERI model may thus be more successful in explaining the adverse consequences of 
work stress in teaching. This implicates that improving social interaction with colleagues and supervisors should be considered in promotion of teacher mental wellbeing. It is, however, noteworthy that increasing support and respect from colleagues and supervisors alone may not be enough because student behavior and misconduct can also be important factors that influence teachers' perception of support and respect they receive.

Opposite to our hypothesis and the results obtained in previous research (Elovainio et al., 2010, 2013, 2003), organizational injustice was not associated with sleep problems or depressive symptoms in the current study. The results might be explained by some of the distinguishing characteristics of teachers' profession. It is possible that organizational justice does not play a particularly important role in teachers' occupational setting because teaching entails usually independent decision-making and professional freedom, the amount of working hours is regulated, and the pay is typically negotiated collectively. It is also possible that because of the small sample the study lacked statistical power to detect the effects of organizational injustice.

With regard to stressful psychosocial work environment and impaired sleep, higher job strain and effort-reward imbalance were associated with only one of the components of sleep problems, that is, nonrestorative sleep. This provides partial support to the findings by Cropley et al. (2006), who found higher job strain to be associated with poor sleep quality among teachers. Teachers' experiences of nonrestorative sleep (i.e., waking up feeling tired and worn out after the usual amount of sleep) may reflect the strenuous effects of workrelated stress: either a normal amount of sleep is not sufficient for recovery or the sleep quality is compromised.

Finally, our hypothesis that sleep problems have a mediating role in the relationship between stressful psychosocial work environment and depressive symptoms received partial support. Job strain and effort-reward imbalance were associated with depressive symptoms directly but also indirectly through nonrestorative sleep, although the indirect effect was relatively weak. The indirect effect through nonrestorative sleep was greater in the relationship between job strain and depressive symptoms in comparison to the indirect effect between effort-reward imbalance and depressive symptoms. As described earlier, the differences in the construct of the job strain and the ERI model may offer explanation for these findings. 
The present study has limitations that should be considered when interpreting the results. Most importantly, the cross-sectional design of our study does not allow making causal inferences. Nevertheless, the directions of temporal associations between the work-related psychosocial factors, sleep, and poor mental health have been reported in previous research (Baglioni et al., 2011; Nieuwenhuijsen et al., 2010; Van Laethem et al., 2013), although there is also some evidence of a reciprocal relationship between them (Armon, Shirom, Shapira, \& Melamed, 2008; Hanson et al., 2011; Lang, Bliese, Lang, \& Adler, 2011). Because the data was gathered with a self-report questionnaire, common method variance may be a concern. Future studies would benefit from objective measures of sleep problems (e.g., polysomnography) when examining the associations between teacher stress, sleep, and depressive symptoms.

The response rate could be roughly evaluated around 20\%. Despite this, the age and gender distributions of teachers were comparable to national age and gender distributions among teachers in Finland. To further evaluate the potential influence of nonresponse bias on the present results, we compared the results to those obtained in other studies because response rates alone are not generally the best indicators of nonresponse bias (Wagner, 2012). The level of effort-reward imbalance seemed to be somewhat higher in comparison to another study examining work stress in teaching using a similar measure (Hinz et al., 2016), indicating that teachers experiencing higher work stress may be overrepresented in our sample. However, the levels of organisational justice and job strain observed in the current study were comparable to previous studies using similar measures (Perko \& Kinnunen, 2013; Yang et al., 2012). Considering limitations, our results can be applied to teachers' occupational context and especially to primary school teachers who experience work stress.

Despite the limitations, our study has also notable strengths. We used multiple validated models of stressful psychosocial work environment and were thus able to compare the suitability of these measures to describe stress in primary school teachers' occupation. From a statistical analyses point of view a further strength was the use of bootstrap analysis in testing the indirect effects and the use of relative weight analysis in examining the proportionate contributions of multiple predictor variables. The current study also complements prior research by examining the mediating role of sleep problems in the association between stressful psychosocial work environment and depressive symptoms in teachers' occupational setting. 
Our results can be interpreted as a spillover of work stress into leisure time, as the inability to unwind or disengage from work may affect recovery in terms of compromised sleep quality. This inability to disengage from work can manifest itself as rumination (i.e., perseverative cognitions), which has been proposed to mediate the relationship between stressful work characteristics and impaired sleep (Berset, Elfering, Lüthy, Lüthi, \& Semmer, 2011). Future research exploring also the role of recovery and rumination could enhance our understanding of stress and the development of depressive symptoms in teachers' occupation.

In conclusion, we found that that particularly high effort-reward imbalance but also high job strain were associated with depressive symptoms among primary school teachers. In addition to the direct associations, job strain and effort-reward imbalance were associated with depressive symptoms also indirectly through nonrestorative sleep. Our results suggest that work stress might have an adverse effect on teachers' sleep quality and prevent sufficient recovery. Consequently, together with work stress, impaired sleep can contribute to the development of depressive symptoms. Adjusting the demanding aspects of teachers' work environment and increasing the rewarding elements, such as the respect and support the teacher receives, could be important in primary school teacher stress prevention. Interventions that focus on teachers' ability to cope with a stressful psychosocial work environment and reduce sleep problems may also help primary school teachers to maintain their mental wellbeing.

\section{Acknowledgements}

This work was supported by the Kone Foundation (K.G., S.M., and T.H.) and the Academy of Finland (projects 265977 (M.E.) and 258711 (L.K.-J.)). 


\section{References}

Amschler, D. H., \& McKenzie, J. F. (2010). Perceived Sleepiness, Sleep Habits and Sleep Concerns of Public School Teachers, Administrators and other Personnel. American Journal of Health Education, 41(2), 102-109. doi:10.1080/19325037.2010.10599134

Armon, G., Shirom, A., Shapira, I., \& Melamed, S. (2008). On the nature of burnout-insomnia relationships: a prospective study of employed adults. Journal of Psychosomatic Research, 65(1), 5-12. doi:10.1016/j.jpsychores.2008.01.012

Baglioni, C., Battagliese, G., Feige, B., Spiegelhalder, K., Nissen, C., Voderholzer, U., ... Riemann, D. (2011). Insomnia as a predictor of depression: a meta-analytic evaluation of longitudinal epidemiological studies. Journal of Affective Disorders, 135(1-3), 10-9. doi:10.1016/j.jad.2011.01.011

Bauer, J., Unterbrink, T., Hack, A., Pfeifer, R., Buhl-Griesshaber, V., Müller, U., ... Wirsching, M. (2007). Working conditions, adverse events and mental health problems in a sample of 949 German teachers. International Archives of Occupational and Environmental Health, 80(5), 442-9. doi:10.1007/s00420-007-0170-7

Bebbington, P., Dunn, G., Jenkins, R., Lewis, G., Brugha, T., Farrell, M., \& Meltzer, H. (2003). The influence of age and sex on the prevalence of depressive conditions: report from the National Survey of Psychiatric Morbidity. International Review of Psychiatry, 15(1-2), 74-83. doi:10.1080/0954026021000045976

Beck, A., Steer, R., \& Brown, G. (1996). Manual for the Beck Depression Inventory-II. 1996. San Antonio, TX: Psychological Corporation.

Berset, M., Elfering, A., Lüthy, S., Lüthi, S., \& Semmer, N. K. (2011). Work stressors and impaired sleep: rumination as a mediator. Stress and Health, 27(2), e71-e82. doi:10.1002/smi.1337

Bonde, J. P. E. (2008). Psychosocial factors at work and risk of depression: a systematic review of the epidemiological evidence. Occupational and Environmental Medicine, 65(7), 438-45. doi:10.1136/oem.2007.038430

Calnan, M., Wadsworth, E., May, M., Smith, A., \& Wainwright, D. (2004). Job strain, effortreward imbalance, and stress at work: competing or complementary models? Scandinavian Journal of Public Health, 32(2), 84-93. doi:10.1080/14034940310001668

Colquitt, J. A., Conlon, D. E., Wesson, M. J., Porter, C. O. L. H., \& Ng, K. Y. (2001). Justice at the millennium: A meta-analytic review of 25 years of organizational justice research. Journal of Applied Psychology, 86, 425-445. doi:10.1037/0021-9010.86.3.425 
Cropley, M., Dijk, D.-J., \& Stanley, N. (2006). Job strain, work rumination, and sleep in school teachers. European Journal of Work and Organizational Psychology, 15(2), 181196. doi:10.1080/13594320500513913

Elovainio, M., Heponiemi, T., Kuusio, H., Sinervo, T., Hintsa, T., \& Aalto, A. (2010). Developing a short measure of organizational justice: a multisample health professionals study. Journal of Occupational and Environmental Medicine / American College of Occupational and Environmental Medicine, 52(11), 1068-74. doi:10.1097/JOM.0b013e3181f8447c

Elovainio, M., Kivimäki, M., Vahtera, J., Keltikangas-Järvinen, L., \& Virtanen, M. (2003). Sleeping problems and health behaviors as mediators between organizational justice and health. Health Psychology, 22(3), 287-293. doi:10.1037/0278-6133.22.3.287

Elovainio, M., Linna, A., Virtanen, M., Oksanen, T., Kivimäki, M., Pentti, J., \& Vahtera, J. (2013). Perceived organizational justice as a predictor of long-term sickness absence due to diagnosed mental disorders: results from the prospective longitudinal Finnish Public Sector Study. Social Science \& Medicine (1982), 91, 39-47. doi:10.1016/j.socscimed.2013.05.008

Finnish National Board of Education. (2013). Teachers in Finland 2013. (T. Kumpulainen, Ed.). Tampere.

Geurts, S. A. E., \& Sonnentag, S. (2006). Recovery as an explanatory mechanism in the relation between acute stress reactions and chronic health impairment. Scandinavian Journal of Work, Environment and Health, 32, 482-492. doi:10.5271/sjweh.1053

Greenberg, J. (1990). Organizational Justice: Yesterday, Today, and Tomorrow. Journal of Management, 16, 399-432. doi:10.1177/014920639001600208

Hakanen, J. J., Bakker, A. B., \& Schaufeli, W. B. (2006). Burnout and work engagement among teachers. Journal of School Psychology, 43(6), 495-513. doi:10.1016/j.jsp.2005.11.001

Hanson, L. L. M., Åkerstedt, T., Näswall, K., Leineweber, C., Theorell, T., \& Westerlund, H. (2011). Cross-Lagged Relationships Between Workplace Demands, Control, Support, and Sleep Problems. SLEEP, 34(10), 1403-10. doi:10.5665/sleep.1288

Hayes, A. F. (2013). Introduction to mediation, moderation, and conditional process analysis: A regression-based approach. New York, NY: The Guilford Press.

Hintsanen, M., Kivimäki, M., Elovainio, M., Pulkki-Råback, L., Keskivaara, P., Juonala, M., ... Keltikangas-Järvinen, L. (2005). Job strain and early atherosclerosis: the 
Cardiovascular Risk in Young Finns study. Psychosomatic Medicine, 67, 740-747. doi:10.1097/01.psy.0000181271.04169.93

Hinz, A., Zenger, M., Brähler, E., Spitzer, S., Scheuch, K., \& Seibt, R. (2016). Effort-Reward Imbalance and Mental Health Problems in 1074 German Teachers, Compared with Those in the General Population. Stress and Health, 32(3), 224-230. doi:10.1002/smi.2596

Jansson-Fröjmark, M., \& Lindblom, K. (2010). Is there a bidirectional link between insomnia and burnout? A prospective study in the Swedish workforce. International Journal of Behavioral Medicine, 17(4), 306-13. doi:10.1007/s12529-010-9107-8

Jenkins, C. D., Stanton, B.-A., Niemcryk, S. J., \& Rose, R. M. (1988). A scale for the estimation of sleep problems in clinical research. Journal of Clinical Epidemiology, 41(4), 313-321. doi:10.1016/0895-4356(88)90138-2

Johnson, J. W., \& Lebreton, J. M. (2004). History and Use of Relative Importance Indices in Organizational Research. Organizational Research Methods, 7(3), 238-257. doi:10.1177/1094428104266510

Johnson, S., Cooper, C., Cartwright, S., Donald, I., Taylor, P., \& Millet, C. (2005). The experience of work-related stress across occupations. Journal of Managerial Psychology, 20(2), 178-187. doi:10.1108/02683940510579803

Karasek, R. A. (1979). Job Demands, Job Decision Latitude, and Mental Strain: Implications for Job Redesign. Administrative Science Quarterly, 24(2), 285. doi:10.2307/2392498

Karasek, R. A. (1985). Job content questionnaire and user's guide. Revision 1.1.

Karasek, R. A., \& Theorell, T. (1990). Healthy work: stress, productivity, and the reconstruction of working life. New York, NY: Basic Books.

Kudielka, B. M., Buske-Kirschbaum, A., Hellhammer, D. H., \& Kirschbaum, C. (2004). HPA axis responses to laboratory psychosocial stress in healthy elderly adults, younger adults, and children: Impact of age and gender. Psychoneuroendocrinology, 29(1), 83-98. doi:10.1016/S0306-4530(02)00146-4

Lang, J., Bliese, P. D., Lang, J. W. B., \& Adler, A. B. (2011). Work gets unfair for the depressed: cross-lagged relations between organizational justice perceptions and depressive symptoms. The Journal of Applied Psychology, 96(3), 602-18. doi:10.1037/a0022463

Loerbroks, A., Meng, H., Chen, M.-L., Herr, R., Angerer, P., \& Li, J. (2014). Primary school teachers in China: associations of organizational justice and effort-reward imbalance with burnout and intentions to leave the profession in a cross-sectional sample. $-479-$ 
International Archives of Occupational and Environmental Health, 87(7), 695-703. doi:10.1007/s00420-013-0912-7

Magnusson Hanson, L. L., Chungkham, H. S., Åkerstedt, T., \& Westerlund, H. (2014). The role of sleep disturbances in the longitudinal relationship between psychosocial working conditions, measured by work demands and support, and depression. Sleep, 37(12), 1977-85. doi:10.5665/sleep.4254

McLean, L., \& Connor, C. M. (2015). Depressive Symptoms in Third-Grade Teachers: Relations to Classroom Quality and Student Achievement. Child Development, 86(3), 945-954. doi:10.1111/cdev.12344

Mezuk, B., Eaton, W. W., Albrecht, S., \& Golden, S. H. (2008). Depression and Type 2 Diabetes Over the Lifespan: A meta-analysis. Diabetes Care, 31(12), 2383-2390. doi: $10.2337 / \mathrm{dc} 08-0985$

Nieuwenhuijsen, K., Bruinvels, D., \& Frings-Dresen, M. (2010). Psychosocial work environment and stress-related disorders, a systematic review. Occupational Medicine, 60(4), 277-86. doi:10.1093/occmed/kqq081

Perko, K., \& Kinnunen, U. (2013). Hyvinvointia edistävä johtajuus: Kahden vuoden seurantatutkimus kunta-alalla [Leadership and wellbeing among municipal employees: A longitudinal study]. University of Tampere.

Preacher, K. J., \& Hayes, A. F. (2008). Asymptotic and resampling strategies for assessing and comparing indirect effects in multiple mediator models. Behavior Research Methods, 40, 879-891. doi:10.3758/BRM.40.3.879

Robbins, J. M., Ford, M. T., \& Tetrick, L. E. (2012). Perceived unfairness and employee health: A meta-analytic integration. Journal of Applied Psychology, 97(2), 235-272. doi: $10.1037 / \mathrm{a} 0025408$

Siegrist, J. (1996). Adverse health effects of high-effort/low-reward conditions. Journal of Occupational Health Psychology, 1, 27-41. doi:10.1037/1076-8998.1.1.27

Siegrist, J., Starke, D., Chandola, T., Godin, I., Marmot, M., Niedhammer, I., \& Peter, R. (2004). The measurement of effort-reward imbalance at work: European comparisons. Social Science and Medicine, 58, 1483-1499. doi:10.1016/S0277-9536(03)00351-4

Steinhardt, M. A., Smith Jaggars, S. E., Faulk, K. E., \& Gloria, C. T. (2011). Chronic Work Stress and Depressive Symptoms: Assessing the Mediating Role of Teacher Burnout. Stress and Health, 27(5), 420-429. doi:10.1002/smi.1394

Tonidandel, S., \& LeBreton, J. M. (2011). Relative Importance Analysis: A Useful 
Supplement to Regression Analysis. Journal of Business and Psychology, 26(1), 1-9. doi:10.1007/s10869-010-9204-3

Van der Kooy, K., van Hout, H., Marwijk, H., Marten, H., Stehouwer, C., \& Beekman, A. (2007). Depression and the risk for cardiovascular diseases: systematic review and meta analysis. International Journal of Geriatric Psychiatry, 22(7), 613-26. doi:10.1002/gps.1723

Van Laethem, M., Beckers, D. G. J., Kompier, M. A. J., Dijksterhuis, A., \& Geurts, S. A. E. (2013). Psychosocial work characteristics and sleep quality: a systematic review of longitudinal and intervention research. Scandinavian Journal of Work, Environment \& Health, 39(6), 535-49. doi:10.5271/sjweh.3376

Wagner, J. (2012). A comparison of alternative indicators for the risk of nonresponse bias. Public Opinion Quarterly, 76, 555-575. doi:10.1093/poq/nfs032

Wang, Y., Ramos, A., Wu, H., Liu, L., Yang, X., Wang, J., \& Wang, L. (2014). Relationship between occupational stress and burnout among Chinese teachers: a cross-sectional survey in Liaoning, China. International Archives of Occupational and Environmental Health, 5(2), 123-128. doi:10.1007/s00420-014-0987-9

Yang, X., Telama, R., Hirvensalo, M., Hintsanen, M., Hintsa, T., Pulkki-Råback, L., ... Raitakari, O. T. (2012). Moderating Effects of Leisure-Time Physical Activity on the Association Between Job Strain and Depressive Symptoms. Journal of Occupational and Environmental Medicine, 54, 303-309. doi:10.1097/JOM.0b013e318240df39

Åkerstedt, T. (2006). Psychosocial stress and impaired sleep. Scandinavian Journal of Work, Environment and Health, 32, 493-501. doi:10.5271/sjweh.1054

Åkerstedt, T., Nilsson, P., \& Kecklund, G. (2009). Sleep and recovery. In S. Sonnentag, P. L. Perrewé, \& D. C. Ganster (Eds.), Current Perspectives on Job-Stress Recovery: Research in Occupational Stress and Well-being, Volume 7 (pp. 205-247). Bingley, UK: JAI Press.

Åkerstedt, T., Nordin, M., Alfredsson, L., Westerholm, P., \& Kecklund, G. (2012). Predicting changes in sleep complaints from baseline values and changes in work demands, work control, and work preoccupation--the WOLF-project. Sleep Medicine, 13(1), 73-80. doi:10.1016/j.sleep.2011.04.015 